\title{
Characteristics of newly-formed cementum following emdogain application
}

\author{
Khalid Al-Hezaimi ${ }^{1,2 *}$, Mansour Al-Askar ${ }^{1,2}$, Abdulaziz Al-Rasheed ${ }^{1,2}$ \\ ${ }^{1}$ Eng. A. B. Bagshan Growth Factors and Bone Regeneration Research Chair, King Saud University, Riyadh, Saudi \\ Arabia; ${ }^{2}$ Department of Periodontology, School of Dentistry, King Saud University, Riyadh, Saudi Arabia
}

\begin{abstract}
Periodontal regenerative techniques have been proposed; however, the outcomes remain debatable. The present investigation assessed the regenerated cementum following enamel matrix derivative application in dehiscence-type defects. Buccal osseous dehiscences were surgically created on the maxillary cuspid, and the second and fourth premolars in five female beagle dogs. The treatment group ( $n=15$ sites) received the enamel matrix derived application, whereas the control groups $(n=15)$ did not. The dogs were sacrificed 4 months following treatment and the specimens were histologically and histometrically examined. The newly formed cementum was uneven in thickness and mineralization, overlapped the old cementum and exhibited functional orientation, cementocyte lacunae and collagen fibril bundles. Most of the histological specimens showed the presence of a gap between the newly formed cementum and the underlying dentin. Control sites did not exhibit any cementum formation. The present study concluded that newly formed cementum is of cellular type and exhibits multiple characteristics.
\end{abstract}

Keywords: regeneration; cementum; enamel matrix protein

International Journal of Oral Science (2011) 3: 21-26. doi: 10.4248/IJOS11009

\section{Introduction}

The periodontium is comprised of an intricate mosaic of cells and proteins that are primarily responsible for the attachment of teeth in the oral cavity [1]. The formation of cementum can be subdivided into cellular and acellular type. The acellular cementum is formed during root development. Acellular cementum contains a secreted matrix of proteins and fibers. As mineralization takes place, the cementoblasts migrate from the cementum, and the fibers remaining along the surface eventually join the developing periodontal ligament. Cellular cementum develops after the majority of the tooth formation is complete and after the tooth occludes with a

*Correspondence: Khalid Al-Hezaimi

Tel: 966 502303000; Fax: 96614677854

E-mail: alhezaim@usc.edu

Received 26 August 2010; Accepted 27 August 2010 tooth in the opposing arch [2]. This type of cementum forms around the fiber bundles of the periodontal ligaments (Sharpey's fibers). The cementoblasts forming cellular cementum become trapped in the cementum they produce.

An alternative approach to obtain periodontal regeneration is to mimic the events that take place during the development of the dental root [3]. There is increasing evidence that the root sheath cells secrete enamel matrix proteins during root formation, and that these proteins are involved in the formation of acellular cementum during nascent tooth development [3-7]. Exposure of cells from the dental follicle to the enamel matrix in vivo induces the formation of a non-cellular, collagenous hard tissue on the surface of the forming root dentin matrix [5]. A derivative of enamel matrix proteins (EMD) is used for periodontal regeneration because these proteins are believed to induce the formation of acellular extrinsic fiber cementum (AEFC) [8]. 
Histologically, regenerative periodontal therapy using EMD results in the formation of new cementum in both the human and animal model [9-18]. However, in the human model, the data is inconclusive regarding the type of repair or regeneration [19-21]. Furthermore, the current information regarding the type of newly-formed cementum (NFC) following various regenerative modalities in humans, is conflicting [13, 18, 22-27]. Findings from previous studies have indicated that, in humans, the cementum formed after treatment with various types of bone grafts or GTR is mainly cellular, and artifacts are often present [9, 22-23, 28]. The lack of artifacts was interpreted as additional evidence of the superior quality of the EMD-induced cementum that formed after other regenerative techniques such as GTR [8].

As data from animal and human biopsies regarding the characteristics of NFC after EMD application is variable, to the best of our knowledge, and none of the available studies have attempted to systematically describe the NFC following EMD application. Therefore, the aim of the present study is to provide additional systematic histological evidence regarding the characteristics of newly formed cementum following EMD application.

\section{Materials and Methods}

Five adult female beagle dogs were used (mean weight $13.4 \mathrm{~kg}$, and age 15 months). The non-surgical and surgical procedures were performed under general anesthesia using $\operatorname{Ketalar}^{\circledR}$ (Pfizer Inc, NY, USA) $10 \mathrm{mg} \cdot \mathrm{kg}^{-1}$ body weight; and local anesthesia using Xylocaine $^{\circledR}$ (Astra, Sweden) with epinephrine $5 \mathrm{mg} \cdot \mathrm{mL}^{-1}$.

\section{Periodontal Surgery}

Supragingival scaling was done using a Cavitron ${ }^{\circledR}$ twice per week during a three weeks housing period prior to any surgery. The surgery consisted of a buccal full thickness mucoperiosteal flap elevation, and the entire soft tissue adherent to the teeth and alveolar bone was removed. Under irrigation with sterile saline, the buccal alveolar bone as well as the exposed periodontal ligament and cementum of three teeth: the canine, second premolar (P2), and fourth premolar (P4) were removed by means of \#6 round carbide bur and hand curettes. The distance between the cementoenamel junction and the apical end of the defect was standardized to $8 \mathrm{~mm}$ and $5 \mathrm{~mm}$ for the canine and premolars, respectively.

The buccal half of the interradicular alveolar bone was also removed to eliminate the possibility of accelerated healing from the adjacent bone and periodontal ligament. A notch on the root surface was made to serve as a landmark for future measurements in the histological sections, and was prepared at the apical level of the surgically reduced bone using a round bur. There were three teeth used per maxillary side, with 15 teeth per treatment variable (with or without Emdogain ${ }^{\circledR}$ ). Using a split mouth design, 30 teeth were assigned randomly to either group evenly: (A) control group - no placement of EMD; (B) test group received EDTA 24\% for two minutes and then application of EMD (Emdogain $\left.{ }^{\circledR}\right)$. The flaps were repositioned to their presurgical level using Vicryl 5-0, FS-2 needle (Ethicon Inc., Somerville, USA).

All animals received intra-muscularly injected Medicycline $^{\circledR}$ vet (Norbrook Lab Ltd., Northern Ireland, UK) $5 \mathrm{mg} \cdot \mathrm{kg}^{-1}$ body weight once a day for three days. The sutures were removed after two weeks. Plaque-control procedures, which included topical application of a $0.2 \%$ chlorhexidine digluconate solution, were performed twice weekly for four months after surgery.

\section{Biopsy, histological processing and analysis}

After four months, the animals were sacrificed with an overdose of sodium pentobarbital $3 \%$, and the segments of the jaws containing the teeth with the buccal dehiscence were removed en bloc along with adjacent teeth and alveolar bone. The blocks were fixed in a $10 \%$ neutral formalin solution for one week. They were decalcified in a solution of equal parts of $50 \%$ formic acid and $20 \%$ sodium citrate for ten weeks. The decalcified specimens were washed in running water, dehydrated and embedded in paraffin. Bucco-lingual sections of $7 \mu \mathrm{m}$ using a microtome with diamond blade were obtained and stained with Retic and Masson's trichrome.

\section{Histomorphometric analysis}

The measurements were performed with a light microscope linked to a video camera/computer/software (Buehler, New Jersey, USA). A comparison was made between the tissue formed in the defect compartments between the control and test sites. The analyses were confined to the NFC and PDL. A new Michigan periodontal probe was placed over a histological section and picture was taken. A $1 \mathrm{~mm}$ portion of the periodontal probe was calibrated to pixels $(0.0023 \times$ number pixels $=\mathrm{mm})$. A $t$-test was used to identify the significance between the two groups.

\section{Results}

Regenerated cementum formed an uneven (mean $0.54 \mathrm{~mm} \pm 0.13 \mathrm{SD}$ ) layer where the thickest section was found at the notch section (Figures 1, 2A) and regularlycontained cementocytes embedded in a colla genous matrix (Figures 2B, 2C). Connective tissue fiber (CTF) bundles were arranged, mainly functionally oriented to the 
original surface of the notches (Figures 1, 2D, 3, 4A, 4D). An interesting histological finding was observed, whereby the NFC differs in the mineralization of different specimens despite the fact that they received the same treatment and for the same duration of time (Figures 1, 2C, 3, 4A, 4B). All sites treated with EMD had formed a cementum compared to the control group $(P<0.000)$.

NFC sometimes separated from the original hard tissues by a continuous layer of heavily contrasted material (Figure 3). This dense material lined the entire surface of the NFC and even extended into small transient dentin resorption areas caused by the use of the round bur (Figures 4A). Regularly, there were also larger splits along the interface between regenerative cementum and original root dentin (Figures 2C, 4C). These splits seemed empty and may have been artifacts due to the separation

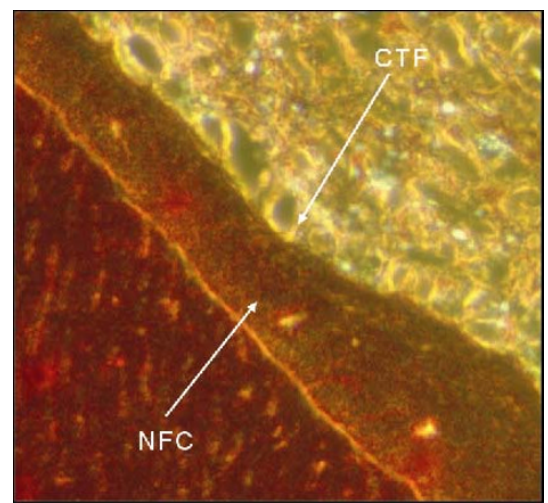

Figure 1 Photomicrograph of NFC after EMD application associated with thickness variation, perpendicular and functionally CTF insertion. Retic stain, $\times 20$.
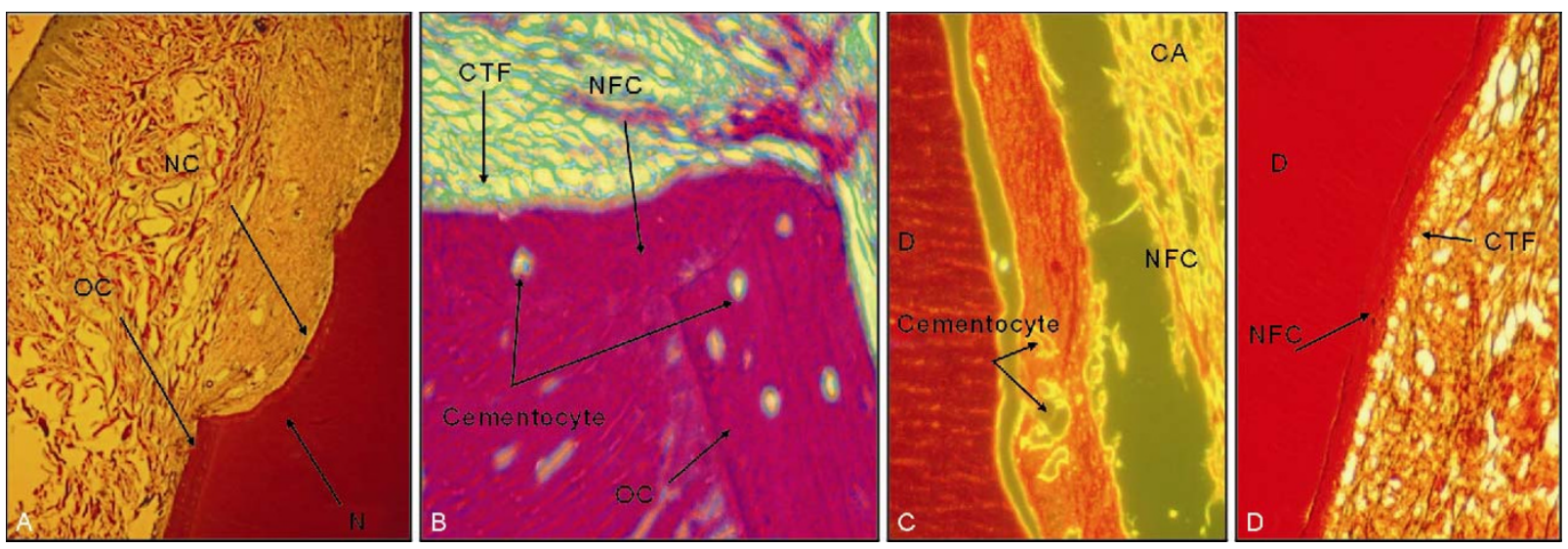

Figure 2 Structure of the newly-formed cementum. (A) Photomicrograph of NFC after EMD application associated with thickness variation, perpendicular and functionally CTF insertion. Retic stain, $\times 20$. (B) Low power photomicrograph showing the notch and the newly formed and old cementum. Retic stain, $\times 4$. (C) NFC with the presence of cementocyte (arrow) at the base of the notch in the premolar defect site. Modified Masson's trichrome stain, $\times 10$. OC: old cementum. (D) NFC shows cementocytes embedded in a collagenous matrix, continuous covering of cementoblast-like cells (arrow), and cementum artifact (CA). Retic stain, ×40. D: dentin.

of new and pre-existing tissues during histological processing or may be due to a weak bond between new cementum (NC) and dentin surface in the absence of dentin resorption. Collagen fibrils of regenerative cementum were often making contact with the fibrils of the underlying dentin (Figures 1, 2D, 4D).

A continuous layer of the NFC extended coronally from the base of the notch (mean $3.74 \mathrm{~mm} \pm 0.43 \mathrm{~mm}$ $\mathrm{SD}$ ), in all specimens of the EMD-treated sites, and the NFC extended apical to the base of the notch and overlapped the old cementum to a average distance between $0.2-0.4 \mathrm{~mm}$ (Figure 4D). The ruffled surface of dentin (Figure 4A) indicated iatrogenic dentin resorption.
Cementum separation presented in the histological specimens in the absence of root resorption (Figure 4C). However, there was no cementum separation in the presence of root resorption. Artifacts were present in 58\% of the histological specimens that were treated with EMD (Figures 2C, 4C). The NFC consistently shows the presence of cementocyte (Figures 2B, 2C, 4A) in all histological specimens. Also, the presence of cementocytes in the old cementum (OC) apical to the notch is explained by the fact that the histological sections were taken from premolar sites where the notch was close to the apex, and apical cementum is of the cellular type. 


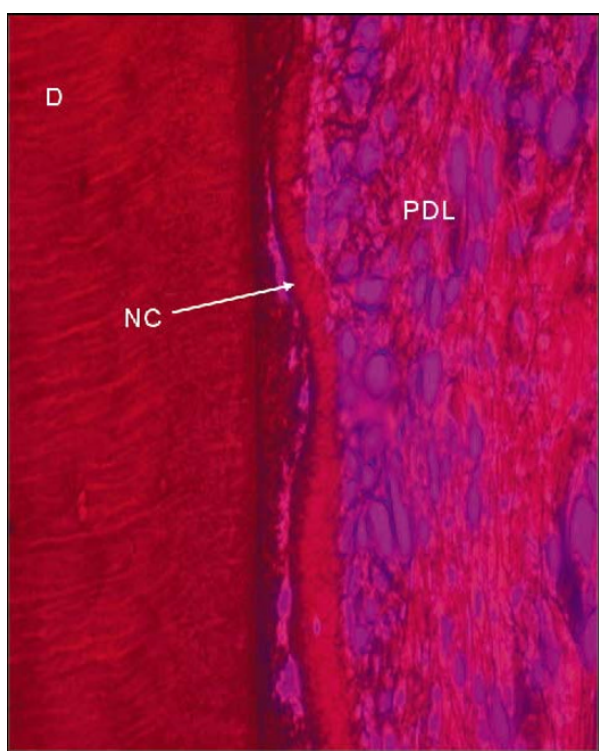

Figure 3 NFC separated by a gap from the preexisting dentin separated by a continuous layer of heavily contrasted material appeared incompletely mineralized. Retic stain, $\times 60$.
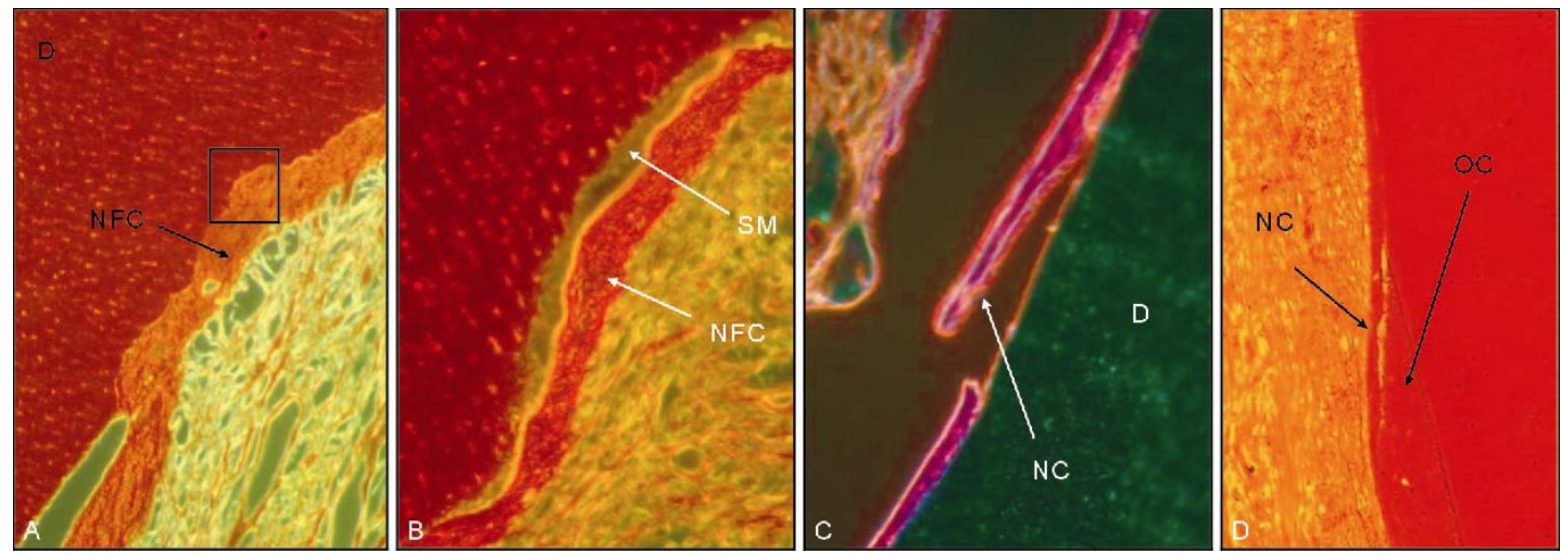

Figure 4 NFC and its relationship with its surrounding structure. (A) Dentin resorption with no separation and immediate coronal to the resorption, an artifact of cementum occurred. Retic stain, $\times 10$. (B) Photomicrograph showing slightly mineralized material (SM) lined the entire surface of the newly formed cementum and even extended into small transient dentin resorption. Retic sayin, $\times 120$. (C) Cementum separation and artifact. Modified Masson's trichrome stain, $\times 80$. (D) NFC overlapped OC with a gap interface between the two layers of cementum. Retic stain, $\times 80$.

\section{Discussion}

When guided tissue regeneration was used, cementogenesis follows in at least two distinct patterns. In the first pattern, a fringe of collagen fibrils oriented more-or-less perpendicular to the pre-existing root surface is formed initially. This fringe seems to be created by cells resembling cementoblasts, which gradually becomes mineralized. In contrast, in the second pattern of regenerative cemen- togenesis, there is an accumulation of sheets of collagen fibrils arranged largely-parallel to the root surface, running both axially and circularly [23]. Cementoblastlike cells, that are occasionally seen embedded in their secretion as cementocytes, apparently also produce this matrix. In our study, the new cellular cementum shows cementocyte lacunae in most of the specimens.

The regenerated cementum contained cementocytes and was covered by cementoblast-like cells. However, in contrast to the intrinsic fibers of the cellular cementum 
that had formed during root development, with collagen fibrils arranged randomly [29], the NFC in our study exhibited fibrils running largely-perpendicular to the exposed dentin surfaces. Furthermore, our histological observation of the NFC shows that the NFC rarely adheres to the underlying dentin because there is an intervening thin layer of afibrillar, dense material, which is generally lacking an attachment to dentin. Moreover, uneven mineralization, which was found in many of the histological specimens for the NFC, has not previously been reported.

An artificial split between the NF tissue and the root surface suggests a weak connection between the two tissues. Such light microscopic splits seem to commonly occur in non-guided repair [30] and healing under (GTR) [31-33]. Recent studies of GTR also suggested that the formation of these artifacts did not depend on whether or not the root surfaces had been exposed surgically [33] or were exposed as a result of periodontitis [31, 34]. Separation of regenerative cementum from the underlying dentin could not be prevented by the employment of growth and differentiation factors [35-36]. At the ultrastructural level, it was showed that artifact splits were microscopically associated with the presence of an electron-dense, granular, and non-collagenous layer at the interface between old and new tissue $[30,37]$.

\section{Conclusion}

The results show that a NFC can occur following EMD application in the Canine model in areas of dehiscence. The NFC has variety of characteristics and the type of the NFC is cellular. The type of NFC was consistent in all the histological specimens.

\section{Acknowledgements}

Special thanks to Dr. Paul Levi for his help in the manuscript preparation. The project was supported by grant from Eng. A. B. Growth Factors and Bone Regeneration Research Chair and number \#LR0003.

\section{References}

1 Mariotti A. The extracellular matrix of the periodontium: dynamic and interactive tissues. Periodontol 2000 1993; 3: 39-63.

2 Zeichner-David M. Regeneration of periodontal tissues: cementogenesis revisited. Periodontol 2000 2006; 41: 196217

3 Slavkin HC. What is the role of the host in periodontal disease? Periodontal Abstr 1975; 23: 101-103.
4 Lindskog S. Formation of intermediate cementum. II: a scanning electron microscopic study of the epithelial root sheath of Hertwig in monkey. J Craniofac Genet Dev Biol 1982; 2: 161-169.

5 Fong CD, Hammarstrom L. Expression of amelin and amelogenin in epithelial root sheath remnants of fully formed rat molars. Oral Surg Oral Med Oral Pathol Oral Radiol Endod 2000; 90: 218-223.

6 Paine ML, Snead ML. Tooth developmental biology: disruptions to enamel-matrix assembly and its impact on biomineralization. Orthod Craniofac Res 2005; 8: 239-251.

7 Wang H, Tannukit S, Zhu D, Snead ML, Paine ML. Enamel matrix protein interactions. $J$ Bone Miner Res 2005; 20: 1032 1040.

8 Hammarstrom L. Enamel matrix, cementum development and regeneration. J Clin Periodontol 1997; 24: 658-668.

9 Bowers GM, Chadroff B, Carnevale R, et al. Histologic evaluation of new attachment apparatus formation in humans. Part I. J Periodontol 1989; 60: 664-674.

10 Bowers GM, Chadroff B, Carnevale R, et al. Histologic evaluation of new attachment apparatus formation in humans. Part II. J Periodontol 1989; 60: 675-682.

11 Bowers GM, Chadroff B, Carnevale R, et al. Histologic evaluation of new attachment apparatus formation in humans. Part III. J Periodontol 1989; 60: 683-693.

12 Hammarstrom L, Heijl L, Gestrelius S. Periodontal regeneration in a buccal dehiscence model in monkeys after application of enamel matrix proteins. J Clin Periodontol 1997; 24: 669-677.

13 Heijl L. Periodontal regeneration with enamel matrix derivative in one human experimental defect. A case report. J Clin Periodontol 1997; 24: 693-696.

14 Camelo M, Nevins ML, Schenk RK, et al. Clinical, radiographic, and histologic evaluation of human periodontal defects treated with Bio-Oss and Bio-Gide. Int J Periodontics Restorative Dent 1998; 18: 321-331.

15 Heard RH, Mellonig JT. Regenerative materials: an overview. Alpha Omegan 2000; 93: 51-58.

16 Sculean A, Chiantella GC, Windisch P, Donos N. Clinical and histologic evaluation of human intrabony defects treated with an enamel matrix protein derivative (Emdogain). Int $J$ Periodontics Restorative Dent 2000; 20: 3743-3781.

17 Lindhe J, Karring T, Lang NP. Clinical periodontology and implant dentistry. 4th Edition. Oxford: Blackwell Munksgaard, 2003.

18 Sculean A, Stavropoulos A, Berakdar M, et al. Formation of human cementum following different modalities of regenerative therapy. Clin Oral Investig 2005; 9: 58-64.

19 Schroeder HE. Biological problems of regenerative cementogenesis: synthesis and attachment of collagenous matrices on growing and established root surfaces. Int Rev Cytol 1992; 142: $1-59$. 
20 Bosshardt DD, Schroeder HE. Cementogenesis reviewed: a comparison between human premolars and rodent molars. Anat Rec 1996; 245: 267-292.

21 Bosshardt DD, Sculean A, Windisch P, Pjetursson BE, Lang NP. Effects of enamel matrix proteins on tissue formation along the roots of human teeth. $J$ Periodontal Res 2005; 40: 158-167.

22 Gottlow J, Nyman S, Lindhe J, Karring T, Wennstrom J. New attachment formation in the human periodontium by guided tissue regeneration. Case reports. J Clin Periodontol 1986; 13: 604-616.

23 Luder HU, Zappa U. Nature and attachment of cementum formed under guided conditions in human teeth. An electron microscopic study. J Periodontol 1998; 69: 889-898.

24 Sculean A, Windisch P, Keglevich T, et al. Clinical and histologic evaluation of human intrabony defects treated with an enamel matrix protein derivative combined with a bovinederived xenograft. Int J Periodontics Restorative Dent 2003; 23: 47-55.

25 Sculean A, Stavropoulos A, Windisch P, et al. Healing of human intrabony defects following regenerative periodontal therapy with a bovine-derived xenograft and guided tissue regeneration. Clin Oral Investig 2004; 8: 70-74.

26 Mellonig JT. Enamel matrix derivative for periodontal reconstructive surgery: technique and clinical and histologic case report. Int J Periodontics Restorative Dent 1999; 19: 8-19.

27 Mellonig JT. Human histologic evaluation of a bovinederived bone xenograft in the treatment of periodontal osseous defects. Int J Periodontics Restorative Dent 2000; 20: 19-29.

28 Dragoo MR, Sullivan HC. A clinical and histological evaluation of autogenous iliac bone grafts in humans. I. Wound healing 2 to 8 months. J Periodontol 1973; 44: 599-
613.

29 Bosshardt DD, Schroeder HE. Initial formation of cellular intrinsic fiber cementum in developing human teeth. A lightand electron-microscopic study. Cell Tissue Res 1992; 267: 321-335.

30 Listgarten MA. Electron microscopic study of the junction between surgically denuded root surfaces and regenerated periodontal tissues. J Periodontal Res 1972; 7: 68-90.

31 Zappa U. Resorbable membranes (I). Periodontal tissue regeneration by the use of resorbable membranes - the clinical aspects. Schweiz Monatsschr Zahnmed 1991; 101: 1146-1153.

32 Zappa U. Resorbable membranes (II). Periodontal tissue regeneration with the use of resorbable membranes - the histological aspects. Schweiz Monatsschr Zahnmed 1991; 101: 1320-1326.

33 Pontoriero R, Nyman S, Ericsson I, Lindhe J. Guided tissue regeneration in surgically-produced furcation defects. An experimental study in the beagle dog. J Clin Periodontol 1992; 19: $159-163$.

34 Dyer BL, Caffesse RG, Nasjleti CE, Morrison EC. Guided tissue regeneration with dentin biomodification. J Periodontol 1993; 64: 1052-1060.

35 Bowers G, Felton F, Middleton C, et al. Histologic comparison of regeneration in human intrabony defects when osteogenin is combined with demineralized freeze-dried bone allograft and with purified bovine collagen. $J$ Periodontol 1991; 62: 690-702.

36 Ripamonti U, Heliotis M, van den Heever B, Reddi AH. Bone morphogenetic proteins induce periodontal regeneration in the baboon (Papio ursinus). J Periodontal Res 1994; 29: 439-445.

37 Listgarten MA. A light and electron microscopic study of coronal cementogenesis. Arch Oral Biol 1968; 13: 93-114. 